\title{
Methods to conduct and analyse weed surveys in arable farming: a review
}

\author{
Kristin Hanzlik $^{1,2}$ • Bärbel Gerowitt ${ }^{1}$
}

Accepted: 16 December 2015 / Published online: 10 February 2016

(C) INRA and Springer-Verlag France 2016

\begin{abstract}
Arable weeds always accompany arable farming; however, species and abundances vary in space and change in time. Surveys assess weeds on a large spatial scale. The regional and national importance, the abundances in which weeds occur, is derived from surveys. Environmental and management background data assist to explain the weed vegetation. Arable weed surveys can have an agronomic, a botanical or an ecological purpose - we approach the agronomic viewpoint. Scientific value results from spatial data about the arable weed vegetation for modelling the dependencies and predicting future changes on a large scale. Researchers, botanists, farmers, advisors, herbicide manufacturers and other industry players engaged in weed control can get rationale spatial impressions of trends in the weed vegetation. This review focuses on methodical aspects of weed surveys. Forty-three surveys on farmed fields, mainly but not exclusively undertaken in Europe, done in up to nine crops per survey covering periods of 1 to 67 years and including 59 to 4423 fields were excerpted for suitable methods to conduct and analyse surveys. The methods reflect agronomic and other targets, e.g. from vegetation science. When accessing existing data, the interdependencies of the layout and all targets should be handled with care. When setting up surveys for agronomic purpose, it is worthwhile to include 3 years and apply stratified sampling. We recommend assessing abundances rather
\end{abstract}

Bärbel Gerowitt

baerbel.gerowitt@uni-rostock.de

1 Group Crop Health, Faculty of Agricultural and Environmental Sciences, University of Rostock, Satower Str. 48, 18051 Rostock, Germany

2 Present address: BASF Aktiengesellschaft, Carl-Bosch-Strasse 64, 67117 Limburgerhof, Germany than presence only. Weed survey data is most suitable for applying multivariate statistics. We recommend using proven methods, without discouraging to explore others. To collect sound explanatory data demands for robust contacts with land managers. Explanatory variables are important in survey analyses to extract knowledge about the drivers of the weed vegetation. We conclude that extra value can be obtained from existing weed survey data. We propose to setup public-private partnerships as a way to carry on with arable weed surveys.

Keywords Arable weed vegetation $\cdot$ Abundance $\cdot$ Cover . Diversity · Sampling · Multivariate statistics · Europe . Monitoring $\cdot$ Mapping

\section{Content}

1 Introduction

2 Reviewed surveys - crops, time, site and field aspects

2.1 Selection of surveys

2.2 Crops surveyed

2.3 Time scale aspects

2.4 Site or field numbers

2.5 Distribution of sampled fields

2.6 Conclusions

3 Recording vegetation and explanatory data

3.1 Sampling season

3.2 Herbicide applications

3.3 Assessments of abundance

3.4 Size and distribution of sampling units

3.5 Collecting data for potential explanatory variables 3.6 Conclusions 
4 Interpretation and statistical analysis of survey data

4.1 Depending weed variables and explanatory variables 4.2 Mapping

4.3 Measurements of diversity

4.4 Multivariate statistics

4.5 Conclusions

5 Summarizing survey results

6 Conclusions

Acknowledgments

References

\section{Introduction}

Arable land use with mainly annual, occasionally perennial crops is always accompanied by arable weeds - spontaneously emerging plants, mostly annual, some perennial species adapted to arable conditions. While weeds in general are omnipresent under arable use, occurrences and abundances of species differ in space and change in time. Though weeds are indispensable parts of arable systems, farmers take much effort to control them in order to ensure long-term yield quantity and quality, regardless of the type of cropping systems. Weeds are the only spontaneous contribution of arable sites to plant diversity that makes their nature even more doublesided, as they also ensure ecosystem services (Médiène et al. 2011) or are themselves targets of conservation (Meyer et al. 2013).

Surveys or monitoring programmes assess organisms on a large spatial scale - for arable weeds concentrating on arable fields as habitat. The weed vegetation in arable systems of the old world has developed over centuries and thereby supported own and unique multi-species plant communities (Holzner and Immonen 1982). Hence, weed surveys in these arable systems evolved over centuries always delve into a multitude of species, the diversity and the communities they build. This task of arable weed surveys is different from environmental weed surveys as reported by Barnet et al. (2007), which focus single invasive species.

The local, regional and national importance of weed species and the assemblages they perform can be derived from survey data. Processed and aggregated with suitable statistical methods, survey data is helpful to explain why weed species occur and in which assemblages (Fig. 1). Information of weed surveys is valuable for farmers, advisors, herbicide industries and other industries engaged in weed control techniques in order to get reasonable spatial impressions of trends in the current weed vegetation. In research, weed survey data is required for any attempt to model or predict future changes of the arable weed vegetation on a large scale.

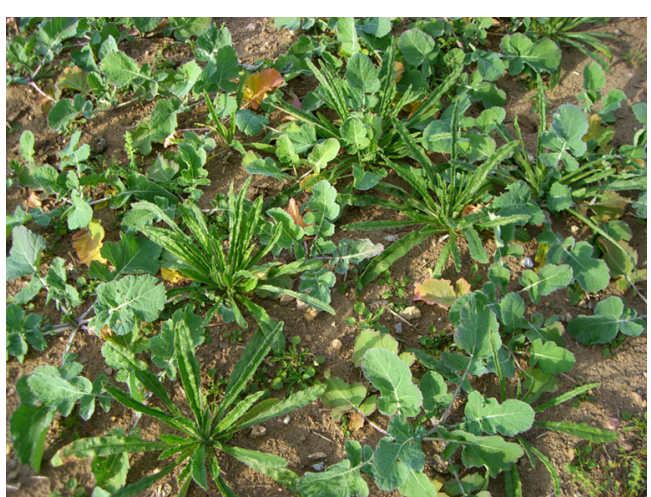

Fig. 1 Weed species adapted to oilseed rape (Anchusa arvensis)

Traditionally, arable weed surveys were an action field for vegetation botanists; in Central Europe specifically, the discipline of plant sociology was developed. Extensive collections of relevés from arable land mainly served to systematically describe and examine the vegetation and thus provided the basis for various phytosociological approaches (BraunBlanquet 1964; Holzner and Immonen 1982; Hüppe and Hofmeister 1990; Glemnitz et al. 2000).

During the last decade, organised large-scale surveys received increasing interest because of their wide scope of application. This includes the integration of weed surveys into national monitoring programmes to assess the overall effect of intensified and/or changed agricultural practice on farmland biodiversity (Lutman et al. 2009; Andreasen et al. 1996; Salonen et al. 2001). Provided that such surveys are repeated or data are collected continuously over a longer period of time, they can be used to quantify changes in species diversity and abundance (Andreasen and Stryhn 2008; Hyvönen et al. 2003; Potts et al. 2010; Lososová et al. 2004). Due to the large areas they cover, they are also suited to reveal regional differences in weed diversity (Šilc et al. 2009; Šilc 2008; Lososová et al. 2004) as well as the related factors determining the occurrence of rare and valuable species (Fried et al. 2010; Hanzlik and Gerowitt 2011).

In general, the role of 'weeds' for production, habitat and conservation strongly depends on which species and how much individuals of them are present. Targets of surveys differ with respect to these general roles, they can be more agronomic, more botanical or more ecological. To detect rare species, other methods than describing the habitat quality ensured by arable weeds are demanded. Connecting weed data with agronomic purposes requires at least that common production conditions are covered by the surveyed sites. The overall purpose also influences how the arable weed vegetation is assessed and described: the presence of species determines the weed diversity, how these occur together is reflected in weed communities, while weed abundances tell about the dimensions in which weeds occur. 
In large-scale surveys, the targets have implications for both the setup of the survey and the analyses of the data. Moreover, the available resources are of pronounced impact. Although this is true for almost all practical scientific setups, the large scale of arable surveys together with a short annual time frame for observations is challenging and hence influencing the applied methods.

This review focuses on weed surveys from an agronomic viewpoint. Agronomy is served by relating a range of site conditions and cropping measures to weed diversity and species composition (Andersson and Milberg 1998; Lososová et al. 2004; Fried et al. 2008; Šilc et al. 2009) or by providing valuable knowledge of weed species occurrences and their prospering under different conditions (Frick and Thomas 1992; McCloskey et al. 1996). From an agronomic viewpoint, weed surveys are interesting as they can perform as complement to field experiments. Due to the known spatial variation in the weed vegetation, point estimates from field experiments can lead to inconsistent results due to site effects (Derksen et al. 1993; Milberg et al. 2001). The results of a large number of different sites enable to assess these effects in a more realistic way (Andersson and Milberg 1998; Hallgren et al. 1999; Gunton et al. 2011) and thereby assist in any implementation of the experimental outcome. Such observational or 'on-farm' research proved eligible for the exploration of complex problems like the assessment of farming systems differing in cropping histories, chemical input level and tillage operations with respect to their impact on weed communities (Leeson et al. 1999, 2000).

Arable weed surveys help agronomists to characterise the weed flora typical of specific cropping practices (Leeson et al. 2000; Poggio et al. 2004; Hawes et al. 2010), regions (Kuzniewski 1975; Frick and Thomas 1992; Goerke et al. 2008; Novák et al. 2009) or site conditions (Hallgren 1996; Firbank et al. 1998; Andreasen and Skovgaard 2009). They further serve to detect regional changes in weed species composition and to statistically confirm field observations and expert knowledge on species spreading due to changes in agricultural practice and/or climate (Andreasen and Stryhn 2008; Fried et al. 2009; Lutman et al. 2009). Finally, they can be used to derive predictions for potential weed shifts and expected weed problems (Mehrtens et al. 2005; Firbank et al. 1998; Pinke et al. 2011; Peters et al. 2014).

Regarding the large quantity of information on species responses, species-environment and speciesmanagement relations, weed surveys can serve as a tool for the development and improvement of strategies for a sustainable, long-term weed control and the maintenance or even creation of biodiversity in arable land (Derksen 1996). Biodiversity is linked to weed diversity and abundances at different spatial (Firbank et al. 1998; Fried et al. 2008) and temporal scales (Hallgren et al. 1999; Lososová et al. 2004; Májeková et al. 2010).

Sparse and diverse arable weed vegetation can provide a wide range of ecosystem services, including the conservation of soil and water resources and supplying habitats to harmless and beneficial organisms (Médiène et al. 2011). Thus, manipulating weed species composition into a desirable and manageable direction is a basic principle of integrated weed management. For the protection of arable biodiversity and rare plant species, management at various scales appears to be important (Gabriel et al. 2006).

The arable weed vegetation is increasingly regarded and investigated in a landscape context (Petit et al. 2013; Gaba et al. 2010). We here distinguish between 'large-scale' and 'landscape' studies. While the first concentrates exclusively on arable fields, the second takes care of all vegetation elements in a landscape segment, including arable fields. This review is limited to large-scale studies. Obviously, landscape-oriented studies can profit from data of arable weed surveys (Petit et al. 2011).

This review provides an overview about methods used to conduct and analyse weed surveys in an agronomic context. Our goal is to offer ideas and inspiration to weed scientists. We selected surveys and summarise them concerning the general organisation (Section 2: Reviewed surveys - sites, crops and time aspects). Surveying vegetation has a long tradition. Thus, it is not surprising that there are many different methodical approaches. We describe the collection of field data in arable weed surveys (Section 3: Recording field vegetation data). The objective of this article is neither to explain sampling theory nor to give a comprehensive description of sampling methods as done, e.g. by Hayek and Buzas (1997) or Henderson (2003). We briefly discuss pros and cons of sampling techniques and protocols.

Another pronounced aim of this review is to stimulate statistical analyses of survey data which provide aggregated, interpretable results beyond species lists in order to derive more information and support publishing of the results. We therefore describe a variety of mostly multivariate statistical approaches which proved useful for the analysis of large sets of vegetation data in various surveys (see Section 4). This is done elementarily, in order to inspire weed scientists with ideas about analysing weed survey data. Authors more experienced in these techniques provide further help with various books and papers (e.g. Legendre and Legendre 2008; McCune and Grace 2002).

Finally, we summarise some general results of the reviewed surveys (see Section 5). With this section, we attempt to offer examples and applications for surveys and their analyses and thus raise the interest of weed scientists, agronomists and agricultural botanists in these. 


\section{Reviewed surveys - crops, time, site and field aspects}

\subsection{Selection of surveys}

We searched for large-scale arable weed surveys with a distinct agronomical purpose. This purpose is either directly announced as goal or is indicated by analysing explaining variables from arable farming practice. The term 'large scale' is not scientifically defined; we approximated a minimum of 50 sites and a state- or nation-wide distribution of the sites. We screened scientific sources on large-scale surveys; the majority from Europe, but we did not neglect comparable published approaches in other parts of the world. We filtered for surveys on practically farmed fields and excluded surveys which are based on experimental sites. Moreover, we neglected surveys with an exclusive focus on rare and endangered species. Sequentially repeated surveys with this focus are analysed in a review reporting species losses in time (Richner et al. 2015).

Our aim was to rest the review upon different survey examples in terms of geography and applied methods. In some papers, agronomic purposes are linked with targets of vegetation sciences, pronounced in, e.g. Hidalgo et al. (1990), Sutcliffe and Kay (2000), Lososová et al. (2004, 2006b), Pinke and Pál (2008), Šilc et al. (2008) and Májeková et al. (2010). Those were filtered for interesting applications of different methods in both conducting and analysing weed surveys. We collected 43 surveys, from which setup and results have been published at least once. Table 1 informs about crops, time and space aspects, recording vegetation and explanatory variables and the analysing approach. The same survey data is sometimes used in several papers. While all the papers we found are considered in the text, we tried to limit Table 1 to the underlying surveys.

\subsection{Crops surveyed}

Surveys under arable conditions can focus one or few crops but can also intend to compare a number of them. The surveys in Table 1 include up to nine crops, the majority concentrates on one to three crops, nine on one and 11 on three crops. Regarding the crops included, cereals are part of most weed surveys (35); however, various other crops are focused, like oilseed rape (22, Fig. 2), maize (19), beets (17), potatoes (12), peas/beans (8), sunflowers (5) or soybeans (3). Gras ley crops were present in eight surveys and 11 took place on the stubble after harvest. The crops included in a survey strongly determine the sampling season. The number of crops is relevant for the appropriate statistical analyses.

The crop actually grown on the sampled field turned out to be the strongest management filter in many studies (Cimalová and Lososová 2009; Fried et al. 2008; Šilc et al. 2008; Pinke et al. 2012; Poggio et al. 2013). Consequently, it may be advantageous to limit sampling to fields of a certain crop whenever the variation of weed vegetation due to factor 'crop' may disguise other effects that are of major interest for the planned investigation. Whenever the weed diversity of a region should be surveyed and thus different crops are included, the analyses should take care of this effect.

\subsection{Time scale aspects}

We consider two time scale aspects: first the sequential years of surveying and second whether a survey is repeated after a period without information.

The studies summarised in this article rely on a wide range of years which was considered as the survey period. A minimum of 1 and a maximum of 67 years performed as the base for the survey. Four surveys rely on one season only; most frequently, a survey period of 3 years (9) was found. It seems advantageous to conduct a weed survey over at least two, better three seasons in order to take into account seasonal climatic differences which are known to considerably influence the occurrence of some weed species. We recommend this regardless of the numbers of crops involved in the survey.

Although weed surveys are highly valuable when they are repeated after a certain time span, we found only seven examples in our sample where an independently repeated survey was realised (Table 1). In those, the time span between the two surveys ranged from 17 to 47 years (last year to first year). Single surveys which can refer to another survey in the same region usually covered less sequentially surveyed years. Carrying out repeated surveys depends on long-term organised surveying activities and on access to the data of the previous period; this includes weed data but also explaining management variables (see Section 3.5).

\subsection{Site or field numbers}

While crop and time aspects are internationally equally understood, the term 'site' differs in the inherent aspects included. It can describe just a geographical unit or it can include selected soil, environmental and nutrient variables. In vegetation science, the concept of site conditions determining the vegetation has a long and successful tradition. Clustering and using site conditions to explain plant communities build the base for the concept of Ellenberg indicator values (EIV) (Ellenberg et al. 1992). Hence, 'site' in the sense of vegetation science can represent a comprehensive description. Modern arable management is known to strongly equalise site conditions (Meyer et al. 2013). 'Field' is the spatial unit that is managed in the same way by the same person taking the decisions. Hence, the term describes tenure conditions rather than site conditions. Nevertheless, from an agronomy point of view, a field is mostly handled as a site. Our screening of the 43 surveys did not indicate any rational use of the different possible meanings of 


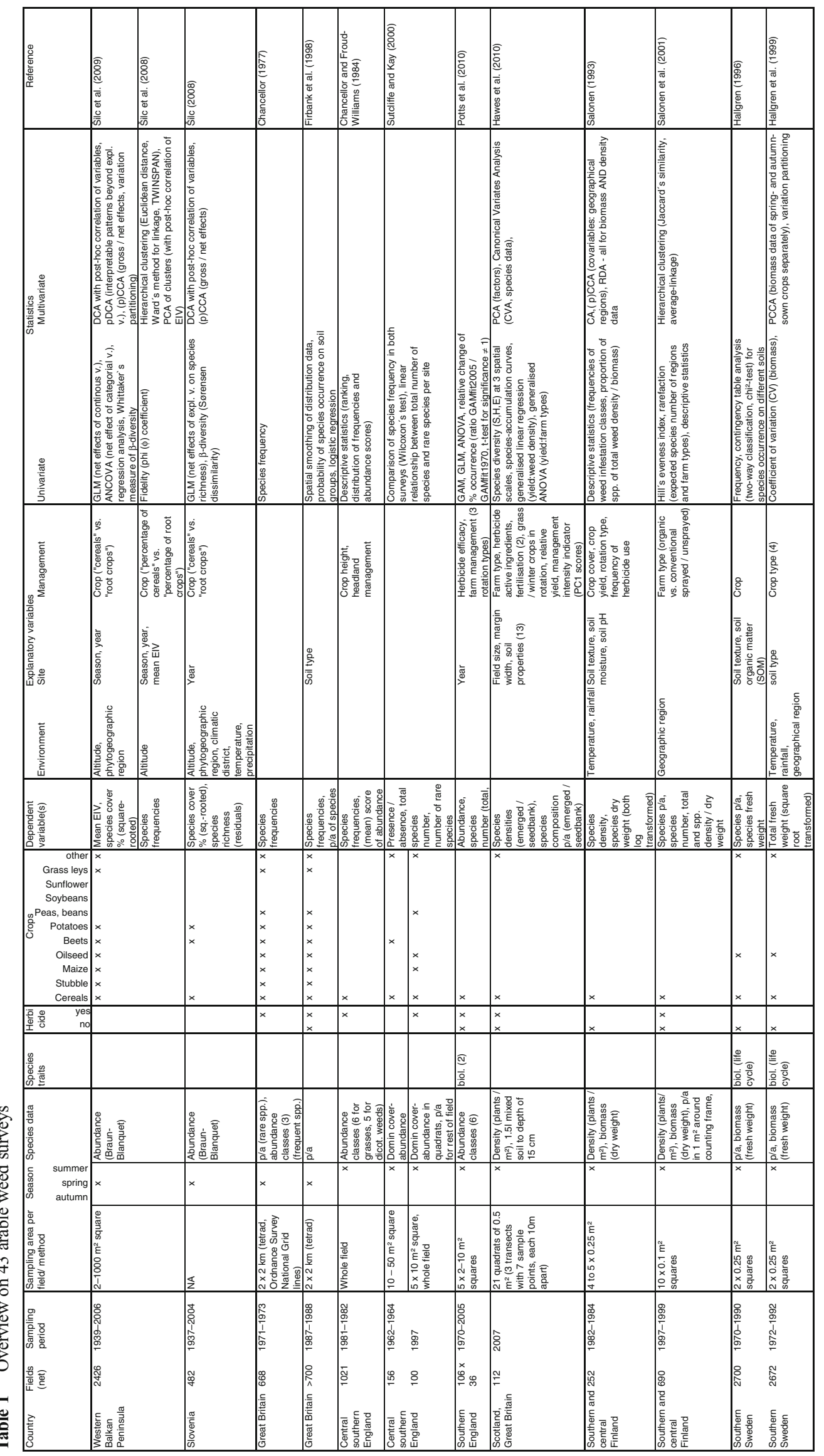




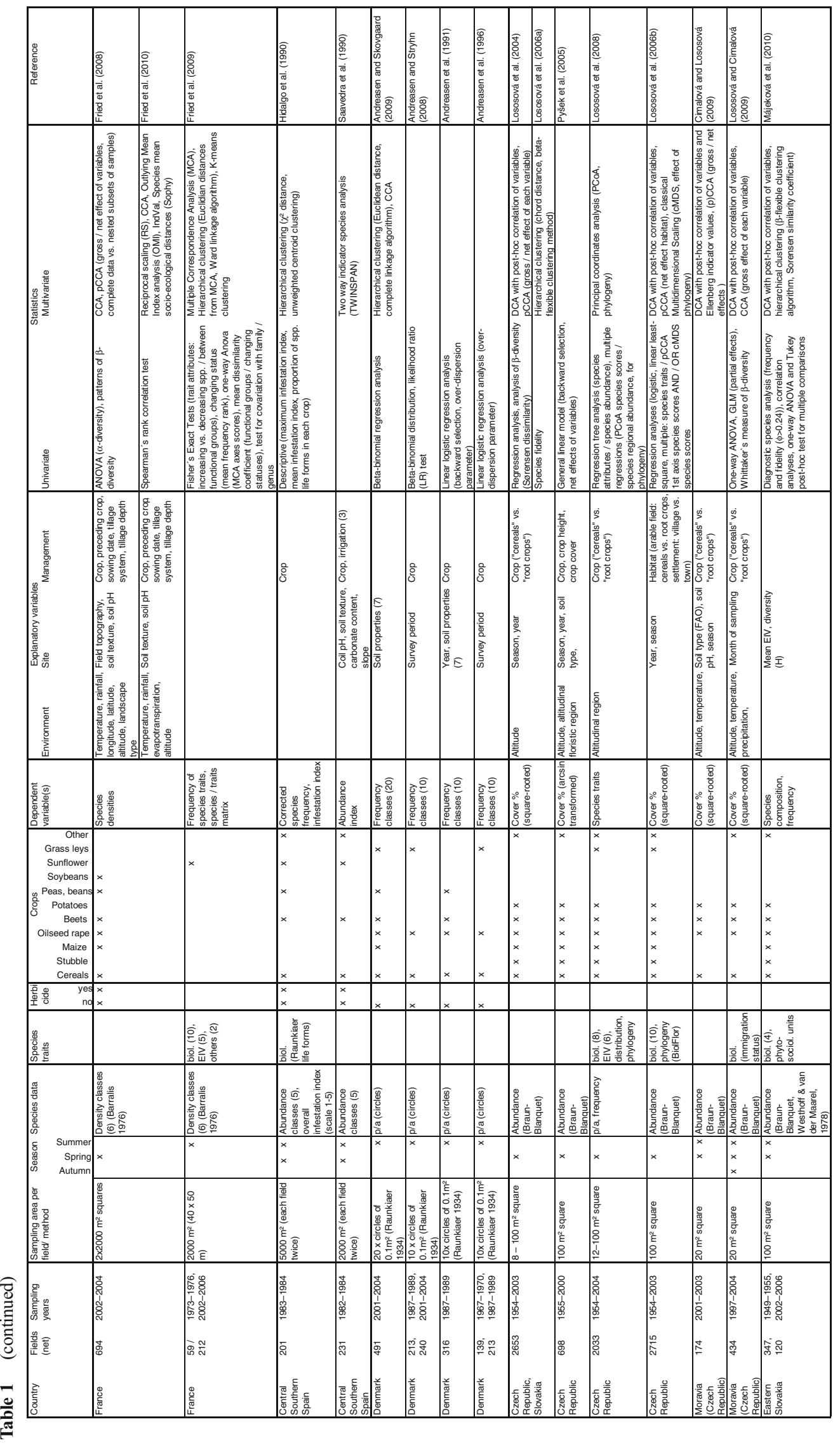




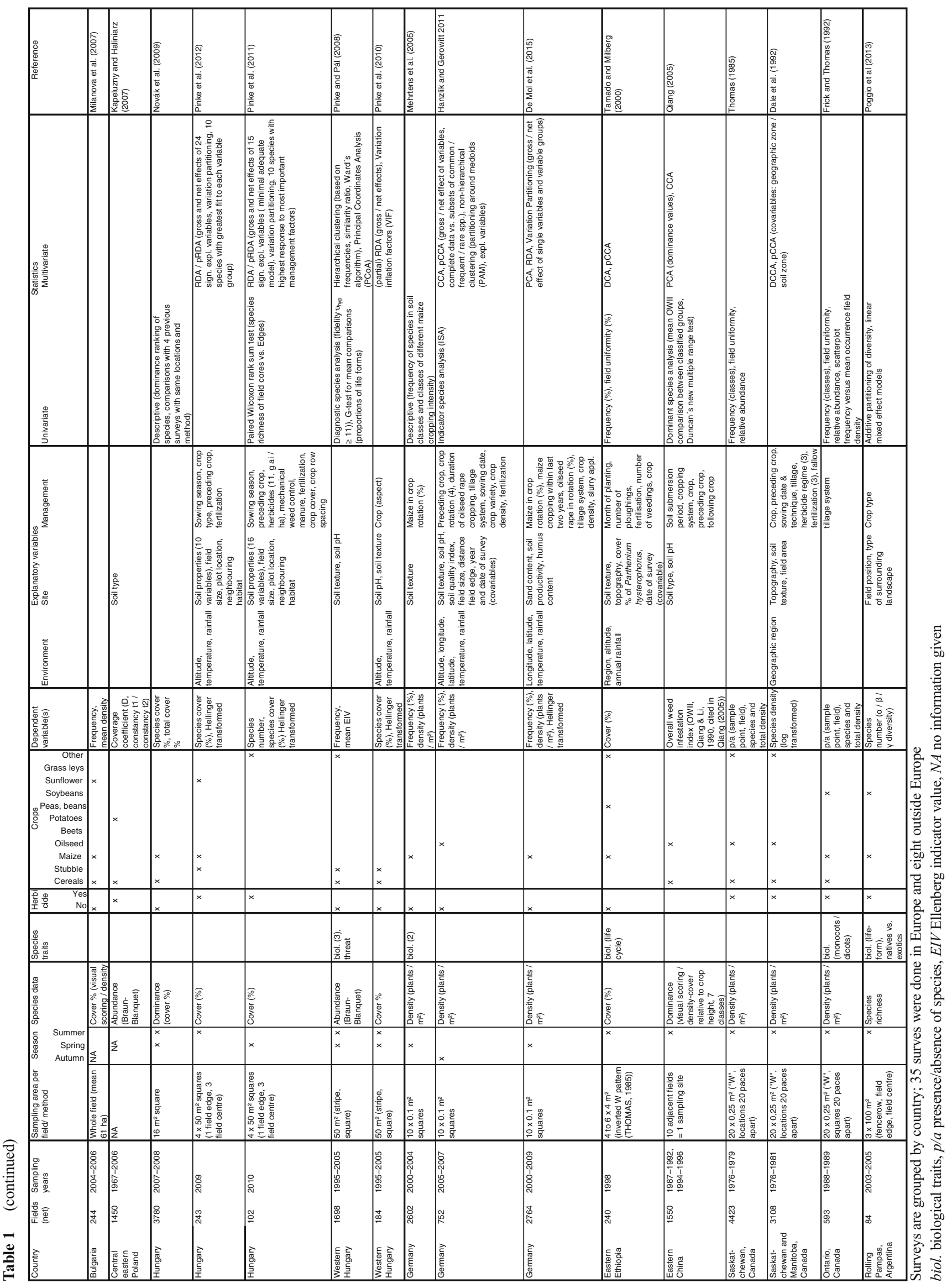




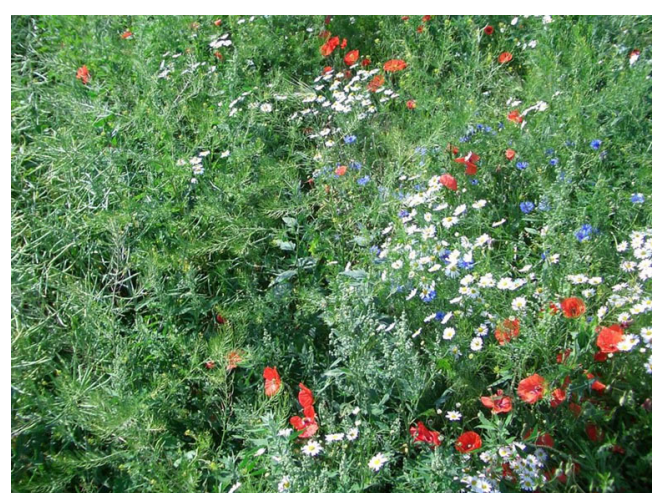

Fig. 2 Diverse weed infestation in a winter oilseed rape field

'site' and 'field' - it appears that it is rather used more or less synonymously. Hence, we handled this in the same way, although we cannot definitely exclude that more than one sampling site is located in one field. The latter may become even more relevant in those parts of Europe where socialistic collectivization after World War II has extremely increased field sizes (Baessler and Klotz 2006). Nevertheless, we use the term 'field' to describe the 'macro-sites' in the surveys, while the 'micro-sites' are subsumed under sampling units in fields in the following Section 3.4.

As mentioned above, the term 'large scale' has not been defined for weed surveys in the literature yet. The general attempt is to cover the entire weed vegetation instead of focusing on single problematic species and usually include at least several hundred arable fields across a landscape or a nation. Surveys in Table 1 included a minimum of 59 sites and a maximum of 4423 . Fifteen surveys rely on up to 250 fields and 15 on more than 1000 fields.

\subsection{Distribution of sampled fields}

A wide variety of fields ensures that cause-effect relationships can be checked for generality (Andersson and Milberg 1998). How this multitude of sites shall be optimally distributed over the study region is an item of discussion. Alternatives to haphazard sampling (often called 'random' though not following a randomisation scheme) are systematic or regular sampling with fields spaced at regular intervals (grid design) (Chancellor 1977; Firbank et al. 1998) or subjective sampling with fields chosen to fit specific criteria, e.g. to 'represent the diversity of cultural practices and environmental conditions present' (Fried et al. 2008) or fit desired farming systems (Leeson et al. 1999). While caution is recommended when subjectively sampled data are used to make objective statements regarding the study area as a whole, systematic sampling of fields was found to yield data that are comparable to those of random sampling for large data sets and even more precise when sampling is done along (environmental) gradients (Hayek and Buzas 1997). Surveying large areas with usually limited resources in time and labour generally calls for organising the sampling. As many other aspects, sampling is shaped by the general goal of the survey. Stratification of sampling fields in the context of weed surveys means to define homogenous subunits (e.g. geographical or administrative regions, crops or tillage systems) within the entirety of locations and to adjust the sampling intensity within these units to reflect their proportion or importance across the whole surveyed area. Deliberate stratification allows the calculation of overall estimates that are highly representative for the whole survey area even if important factors (e.g. the frequency of a sampled crop within different regions) vary substantially (Hayek and Buzas 1997; McCune and Grace 2002). It can also be applied to avoid regional oversampling when working with stored vegetation data from various sources (Lososová et al. 2004; Šilc et al. 2009).

\subsection{Conclusions}

It is not at all surprising that the large-scale surveys differed in their general layout concerning crops, time, site and field aspects; despite that they are done on commonly farmed fields and have an agronomic purpose in general, additional targets of the surveys differed. Additional targets often rooted in vegetation science and focused on deriving phytosociological units for arable weeds. With respect to additional targets of weed surveys, we do not recommend the optimal size and period for surveys on arable weeds. For agronomical purpose, it is worthwhile to include at least 3 years and apply a stratified sampling. Though it is feasible to conduct surveys in all arable crops, strong interdependencies between the chosen crop, the number of crops included and sampling the fields need to be carefully considered when setting up a survey. When existing survey data is accessed, the interdependencies of all the specific targets and the layout should always be handled with care.

\section{Recording vegetation and explanatory data}

In this section, we describe and discuss methodical items of the observation itself that are known to have a considerable impact on the quality and comparability of the collected weed vegetation data and therefore should be considered carefully before conducting a weed survey. These include the sampling season, inclusion or exclusion of herbicide treatment, the numbers of subsamples per site, the choice of a measure of species abundance, the size and design/placement of the sample area and, last but not least, a careful selection of relevant site and management parameters to be measured or collected from interviews. The latter are required as additional explanatory variables in several statistical approaches. 


\subsection{Sampling season}

Weed surveys are mainly undertaken either in autumn, spring or summer (Table 1). Repetition in two or more seasons within a cropping year is not very common. Substantial differences due to different phenological stages of the weed vegetation during the growing season are bound to appear when the survey includes spring and autumn sown crops (Hallgren et al. 1999). Regarding the sampling season, it was found that even within the same crop more variation of the weed vegetation was explained by the season aspect (spring vs. summer) than by any other management or environmental parameter (Pinke et al. 2010). For this reason, the sampling date (described, e.g. as 'month of sampling', 'Julian Day' or by 'growing degree days') ought to be considered when analysing weed vegetation samples from different seasons (Lososová and Cimalová 2009). The time of sampling usually is settled according to the chosen survey conditions. These could be, e.g. maximum ground cover of the crop, completion of all management measures (Leeson et al. 2000; Poggio et al. 2004) or maximum homogeneity of field conditions during flowering (Fig. 3) and seeding of the crop (Thomas 1985; Qiang 2005).

\subsection{Herbicide application}

An issue strongly determining the time of sampling is the decision whether to sample with or without herbicide treatment in the current crop. In the 43 surveys in Table 1, samples were taken in plots without herbicides in 15 , with herbicides in ten cases. Seven surveys had both, samples taken in plots with and without herbicides, while 11 surveys did not report about herbicide use or other direct weed control. Sampling before herbicide treatment records the potential weed vegetation. This is useful to analyse site and management effects other than herbicides. Herbicide effects in the current crop are known to superimpose all other influences (Andreasen et al. 1991; Mehrtens et al. 2005). However, when sampling is done before spraying, a large proportion of the weeds are usually in

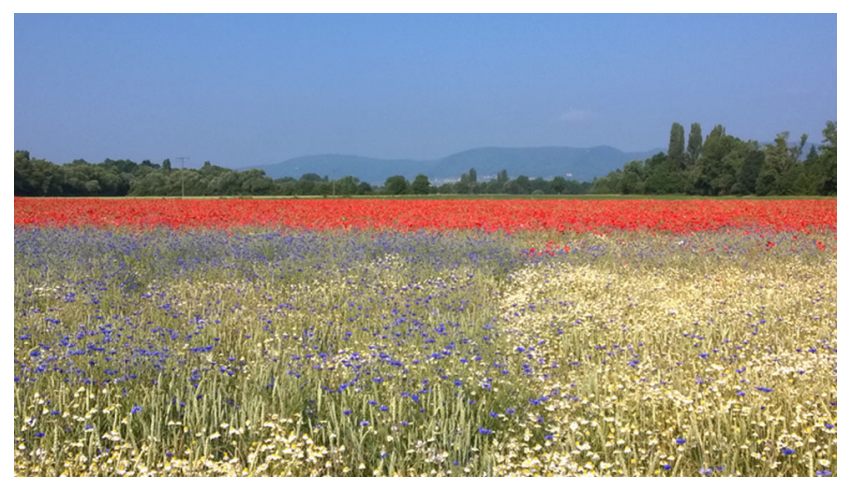

Fig. 3 Late spring weed flowering aspect of a wheat field in Germany very early growth stages. Thus, a reliable distinction of species within the same genus may be impossible. This is a clear disadvantage of early sampling weed data. How severe this disadvantage is strongly depends on the goal of the survey. If the goal is to get an overview of common species or genus, this is acceptable, but if a more precise picture of the plant diversity is wanted, accurate identification on species level is indispensable (Fig. 4). To abandon herbicides during the whole cropping period is particularly required if the potential weed vegetation shall be examined in later phenological stages of the crop or the survey is focused on a precise estimate of weed species diversity. Having large parts of the field with no chemical weed control is unpopular with farmers and thus can complicate the search for fields to be sampled. Frequently, this could be overcome by installing plots with no herbicides, although this method restricts the survey site to small parts of the fields. Sampling after herbicide application is unproblematic in this regard and appropriate when the overall effect of farming systems reflecting the impact of all typical agronomic practices is to be examined (Leeson et al. 1999; Pinke et al. 2011, 2012). A time-consuming but informative alternative is to compare the weed flora in sprayed and unsprayed parts of the fields (Sutcliffe and Kay 2000) or before and after herbicide application (Saaverda et al. 1990; Hidalgo et al. 1990; Fried et al. 2008).

\subsection{Assessments of abundance}

The most commonly used measure of abundance is the estimation of weed cover (Mueller-Dombois and Ellenberg 1974; Poggio et al. 2004) as percentages or by assignment to cover classes (e.g. Pyšek et al. 2005; Aavik et al. 2008) which differ slightly between different existing schemes (McCune and Grace 2002) and usually are transformed into the midpoints of the ranges for further analysis. While weeds were traditionally scored following the scale of Braun-Blanquet (1964), any other scoring scale, existing and citable (e.g. Londo 1976) or self-created, can be used.

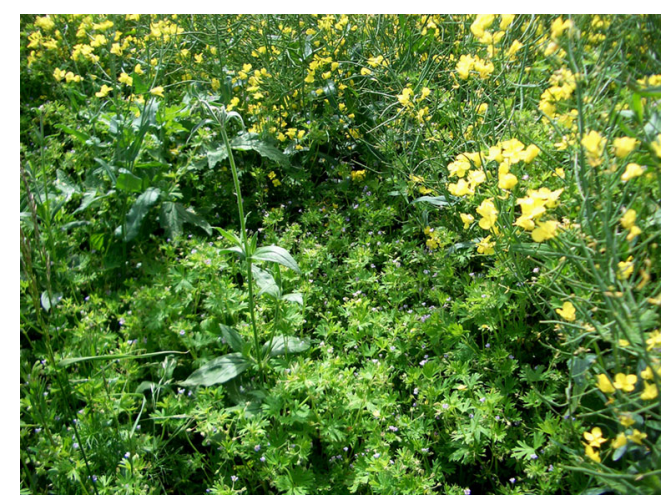

Fig. 4 Some weed species (e.g. Geranium sp.) difficult to distinguish as seedlings can be determined at the species level when assessed late in the season 
The popularity of cover estimation is accounted for by its quickness whilst found to be an effective surrogate for direct biomass measurement (Hermy 1988; Andújar et al. 2010). Disadvantages include the potential for bias between observers (Sykes et al. 1983); however, Andújar et al. (2010) found that visual cover assessment by humans tends to overestimate the weed cover, but they did not report constraining differences between observers. Another issue worth to mention here is the usual need for transformation of cover data and scores before statistical analysis. While this step is required to obtain serious statistical results, understanding plotted or tabulated transformed data demands for a trained mathematical imagination power. Counting individual weeds (plant density) or parts of them (e.g. shoot numbers) within the sampling unit results in precise numerical data ready for statistical analysis but usually means tedious sampling unless weed numbers are estimated according to density classes (Barralis 1976; Chancellor and Froud-Williams 1984; Potts et al. 2010). However, this applies even more to direct weed biomass measurement as done by Hallgren (1996), Hallgren et al. (1999) or Hyvönen et al. (2003). Counting density, estimating cover or measuring biomass assesses different traits of the weed vegetation. Counted individuals are most suitable to be connected to processes which are mainly investigated on a single plant base, while cover and biomass deliver more realistic values for the competitive effects of the weeds. In some situations, counting of individuals is not possible (many monocotyledonous weeds). For perennial weeds, the 'individual' plant can often not be assigned. Parameters like weed cover, number of plants and weed biomass change quickly during the season and consequently require a high level of human resources in order to conduct a weed survey across a larger area within a short period of time. Repeated measurements within one season are rare (Table 1); however, if they are scheduled, the dynamic of the measured variables has to be carefully addressed. When financial limitations are an issue and only a few people are available for sampling, frequency analyses are more suitable to yield data that are comparable throughout the sampling season. Measuring weed frequency as the proportion or percentage of sample units (within a field) in which a weed species occurs (Raunkiaer 1934; Andreasen and Stryhn 2008; Lutman et al. 2009) is fast to score, sensitive to infrequent species and also contains information about spatial distribution. However, it is known to be highly dependent on the size of the sample units (McCune and Grace 2002). The simplest way of sampling weeds is to just record the presence or absence of a species. This is very effective in large-scale studies as it will carry most of the information in heterogeneous sample areas but fails to detect more subtle or local differences. Another kind of measuring weed vegetation is to combine traits directly in the assessment, in such a way that importance of a species is weighted. An advantage of importance values or other combined values of visual scoring is that they yield one (continuous) variable for analysis though taking into account several aspects of weed occurrence, e.g. dominance, relative height and cover (Qiang 2005) or density and cover (Miloanova et al. 2007). However, just these various possible combinations often hamper the interpretation and even more the comparison with other studies (McCune and Grace 2002).

\subsection{Size and distribution of sampling units}

The size of the smallest sampling unit used in the surveys varies to a very considerable extent. Although in many surveys it was decided to have sampling units of less than $1 \mathrm{~m}^{2}$ (15 surveys, Table 1), the total range stretched to more than $1.000 \mathrm{~m}^{2}$ (five surveys). Intermediate sampling unit sizes as they are traditionally used in vegetation science (e.g. 25 to $100 \mathrm{~m}^{2}$ ) are also found frequently (12 surveys). Two surveys reviewed by us did not report about any repeated sampling per field.

Mulugeta et al. (2001) calculated species-area curves, which can be derived if a range of sampling unit sizes was conducted or combined. Though these authors found that an area of $1 \mathrm{~m}^{2}$ contains less than half of the total observed species richness of a field, it is generally recommended to choose many small sample units instead of a few large ones and to include more fields rather than investigate more plots within a field. In this way, one obtains not only a higher level of reproducibility for the same cost (Henderson 2003) but also reasonable estimates of the occurrence of weed species on a large scale in different crops (Andreasen and Skovgaard 2009).

The measure of weed abundance also interacts with the size and design of the sample area/unit. Pollnac et al. (2009) give examples for these interactions. While highly accurate measures like weed density and biomass restrict the size of sampling units and are rarely applied to areas larger than $1 \mathrm{~m}^{2}$, estimation of weed cover and visual scoring can easily be applied to whole fields (Miloanova et al. 2007; Goerke et al. 2007) or even to sampling units including several adjacent fields (Qiang 2005). For those methods not considering the entire field, quadrat sampling is a common practice. Usually, the square sample units are either placed randomly (Hanzlik and Gerowitt 2011; Mehrtens et al. 2005), arranged along transects (Lutman et al. 2009; Hawes et al. 2010; Potts et al. 2010) or form a 'w' pattern within a field (Thomas 1985; Leeson et al. 2000, details in Table 1). Larger sample units are usually walked until no more new species are found (Fried et al. 2008; Poggio et al. 2004). Due to known field edge effects (Marshall and Arnold 1995), the placement of sample units close to field boundaries and headland areas should be avoided except when this is part of the objective. 


\subsection{Collecting data for potential explanatory variables}

Considering additional information on site properties, management options and environmental influences is indispensable for the interpretation of weed vegetation data. Spatial unit of most explanatory variables is the field, in case that several sites per field were included, site properties can have a subfield spatial scale. A variety of parameters that proved to be possible explanatory variables is collected in Table 1 . While site and environmental data like soil type, exposition, longitude, and latitude can often be obtained from official databases or maps, management data can only be collected with the help of farmers. Typical management data considered as background information of surveys characterise crop rotation, soil cultivation, fertilisation and pesticide use.

\subsection{Conclusions}

How and where in the single fields the vegetation is recorded is strongly influenced by the available resources for the survey. Moreover, tying the current survey to former ones determines how variables are recorded. For agronomic purpose, we recommend to assess abundances rather than presence only; these can be densities, cover, biomass or scores. If logistically achievable, assessments of the weed vegetation in herbicide free plots deliver valuable information for agronomic purposes. To collect sound explanatory data, demands for robust contacts with land owner and/or farm managers.

\section{Interpretation and statistical analysis of survey data}

Large-scale surveys entail incredibly large data sets. Usually several sampling years, hundreds to thousands of sampled fields, containing numerous species and sometimes also a large set of potentially useful explanatory variables have to be handled. Thus, one of the main questions when dealing with weed survey data is how to proceed to concentrate the information.

\subsection{Depending weed variables and explanatory variables}

Based on the observed weed attributes (counted density, estimated cover, scores, measured biomass), dependent variables can be directly used as observed (e.g. density, cover) or deduced from the recorded vegetation attributes (e.g. number of species, frequencies, EIV). There are many possible ways of combining, deriving and deducing dependent variables to describe the species composition, the species number and further species-related information (Table 1).

Most surveys referred to in this review used explanatory variables in order to analyse and describe the chosen dependent 'weed variable'. In Table 1, we bulked the explanatory variables into the complexes 'environment', 'site' and 'management' (Table 1). If accounted for, it is most popular to include all three bulks of explanatory variables or at least 'site' and 'management'.

\subsection{Mapping and analyses of single species}

When the geographical distribution or spreading of a species shall be examined, this is commonly done by means of maps. Mapping is a simple method to transfer field observations data records into spatial explicit points on a geographical map. To draw maps is an established method for processing weed survey data. We therefore include it, although it is not in the central focus of this review, because geographic maps mainly refer to single species (Kolářová et al. 2013; Hanzlik and Gerowitt 2012; Novák et al. 2009).

Chorological maps, where a species' presence or absence is recorded anywhere in a grid square of $10 \times 10 \mathrm{~km}$, are generally available in European countries. However, these maps do not differentiate between segetal, ruderal and occurrences in other habitats and thus are not suitable for detailed analyses of arable weed vegetation (Holzner and Immonen 1982). In contrast, distribution maps from surveys on arable land indicate whether a species occurs as a weed in a specific region. This information is not to be underestimated as it is known that there are numerous species which are common weeds in their areas of origin (mostly the Mediterranean) but towards the borders of their geographic ranges are first outcompeted to poorer arable sites and finally restricted to ruderal habitats (Holzner and Immonen 1982). Furthermore, maps from weed surveys can be supplemented with additional information, such as the species abundances (Mehrtens et al. 2005; Goerke et al. 2008; Novák et al. 2009; Hanzlik and Gerowitt 2012), total weed infestation or species richness at the sampled sites, for a better illustration of regional differences or even be used to predict the probability of species occurrences by means of interpolation and spatial smoothing (Firbank et al. 1998).

There exists a multitude of (descriptive and univariate) statistical methods to compare and interpret abundance data of single weed species. Interesting examples include different indices of population change between successive weed surveys (Hyvönen et al. 2003; Fried et al. 2009; Potts et al. 2010; Storkey et al. 2010).

\subsection{Measurements of diversity}

When weed survey data shall be used for the analysis of weed diversity, it is essential that many species are represented in the dataset. One of the central questions is whether the sampling effort has been sufficient to adequately characterise the weed assemblage. A simple and commonly used approach to 
answer this question is a species accumulation curve. It is produced by plotting the cumulative number of found species against a measure of sampling effort (sampling units/sites) and becomes an asymptotic curve provided sufficient samples have been taken (Henderson 2003; Hawes et al. 2010). Species-area relationship can also be used to deal with data sets where the size of sample units is inconsistent (Rosenzweig 1995). Also common and easy is the calculation of several diversity indices taking into account the number of species and their abundances in each sample unit (in detail e.g. Magurran 2004) which then can be used as dependent variables for further analysis. An advantage of using such indices for statistical analysis is that - in contrast to abundance measures - they contain information about the entirety weed vegetation of the field. Moreover, these indices are suitable to apply common univariate statistics like general linear models (GLM) (Potts et al. 2010; Šilc et al. 2008), generalised additive models (GAM) (Potts et al. 2010) or analysis of variance (ANOVA).

The classification of diversity according to Whittaker (1972) into the three type alpha $(\alpha)$, beta $(\beta)$ and gamma $(\gamma)$ diversity provides many possible applications for large-scale weed surveys. While $\beta$ diversity is most obvious as a measure of the extent of change in species along a gradient or between regions (Lososová et al. 2004; Šilc et al. 2009; Fried et al. 2008; Poggio et al. 2004), the large spatial extent of such surveys enables the examination and comparison of all three types, alpha $(\alpha)$, beta $(\beta)$ and gamma $(\gamma)$ diversity at or between different spatial scales within the same data set. This hierarchical partitioning of diversity was described in detail by Gabriel et al. (2006) and applied to larger sets of weed vegetation data by Hawes et al. (2010). Pollnac et al. (2009) use species-area curves to calculate diversity on different scalesin their case not for survey data but for comparison of farming systems with the help of selected fields and trials.

\subsection{Multivariate statistics}

It is known that the occurrence of weeds and the composition of weed communities are determined by a large number of factors that are partly interrelated (Kenkel et al. 2002; Murphy and Lemerle 2006). The identification of complex patterns in the data requires statistical approaches that master the simultaneous observation and analysis of more than one depending variable and therefore are called multivariate statistics. Weed survey data are very suitable for multivariate statistical techniques; thus, 26 of the reviewed 43 survey were analysed with this technique, 20 of them together with univariate methods. While 16 surveys are analysed with univariate statistics, in one survey, no information of the analysing methods is given.

The main differentiation between multivariate techniques is whether their purpose is to assign objects to a number of more or less homogenous groups (classification) or to order species along gradients to find out which species are commonly found associated with each other and what are the factors that structure the community (ordination).

Kenkel et al. (2002) promoted the applicability of ordination methods for weed science. Hence, the use of these techniques, especially detrended correspondence analysis (DCA) (Hill and Gauch 1980) and canonical correspondence analysis (CCA) (Ter Braak 1987), has become quite common for the analysis of weed survey data (Table 1, column 'multivariate statistics'). The choice of a specific method depends on both the scientific purpose and the kind of data available (Table 2). Ordination techniques are either based on models assuming a linear response of variables along gradients or on those assuming a unimodal one. Provided the gradient in the data is long enough, most species show a unimodal response to environmental factors. Thus, unimodal models are often more suitable for ecological data sets (Lepš and Smilauer 2003). Indirect gradient analysis only uses a species by sites matrix, which means that the change in species composition alone is expected to indicate what the most important gradients are. Direct gradient analysis (also termed 'canonical methods'), in contrast, utilises external environmental data additional to the species data and provides information on whether and to which extent species composition is related to our measured variables. The interpretation of ordination results in indirect methods such as CA or DCA (abbreviations see Table 2) can be simplified by a posteriori and passively projecting the effects of explanatory variables onto the ordination diagram which is widely used (e.g. Cimalová and Lososová 2009; Šilc et al. 2009; Májeková et al. 2010). However, canonical methods go one step further as they include the possibility to compute the respective importance of environmental factors both as gross effect and, by applying partial ordination (e.g. pCCA or pRDA; for abbreviations, see Table 2), as net effect corrected for the portion of explained variation shared with other variables (Lososová et al. 2004; Fried et al. 2008; Pinke et al. 2010; Šilc et al. 2009; Hanzlik and Gerowitt 2011). Finally, variation partitioning is a procedure where the explained variation is disassembled into components represented by single or thematically grouped variables. A systematic order of partial ordinations (usually pCCAs, Table 2) is used to compute all unique effects of and shared effects between variables/groups in order to compare their impact on weed species composition. A detailed example of variation partitioning among four single factors is given by Hallgren et al. (1999), diagrammed examples including three groups of variables can be found in Schweiger et al. (2005) and Pinke et al. (2009). When applying variation partitioning, the defined groups should each contain a comparable number of variables to avoid bias due to the known positive correlation between the amount of explained variation and the number of included explanatory variables (Borcard et al. 1992; 
Table 2 Most common ordination methods (abbreviations in bold) with their properties and statistical assumptions

\begin{tabular}{lll}
\hline & Indirect gradient analysis & Direct gradient analysis \\
\hline Linear model & Principal component analysis, PCA & Redundancy analysis, RDA \\
Unimodal model & $\begin{array}{c}\text { Correspondence analysis, } \\
\text { CA }\end{array}$ & $\begin{array}{c}\text { Canonical correspondence analysis, } \\
\text { CCA }\end{array}$ \\
& Detrended correspondence analysis, DCA & $\begin{array}{c}\text { Detrended canonical correspondence } \\
\text { analysis, DCCA }\end{array}$
\end{tabular}

Peres-Neto et al. 2006). A stepwise and demonstrative procedure to determine the underlying factors of spatial distribution of weeds has been described as 'adaptive analysis' by Cousens et al. (2006) and proved to be a helpful tool to analyse spatial data.

Though ordination techniques proved to be very valuable in community ecology, less experienced users of multivariate statistics often tend to be suspicious of this kind of data analysis and especially of how to decide on a specific method. A selective, non-statistical overview of ordination methods with applications for weed research can be found in Kenkel et al. (2002), whereas Hallgren et al. (1999) and McCune and Grace (2002) describe how to assess and enhance the reliability of ordination results and Onofri et al. (2010) give directions for the scientifically accurate publication of multivariate approaches.

Classification and clustering, as the second major approach in multivariate statistics, has been applied to weed survey data, e.g. to examine the extent of similarity between the weed vegetation of various crops (Andreasen and Skovgaard 2009) or to hierarchically subdivide the weed vegetation into homogenous weed communities for comparison with the phytosociological units of current taxonomical systems (Lososová et al. 2006a; Pinke and Pál 2008; Šilc et al. 2008). The clustering of weed species into functional groups according to a variety of species traits enabled Fried et al. (2009) to search for trait combinations that determine the success of a weed species under specific selection pressures. Other approaches that cluster management and environmental data rather than species data target the classification of farm management systems or eco-regions to be then related to weed vegetation (Leeson et al. 1999; Hanzlik and Gerowitt 2011). While in other scientific fields (e.g. molecular biology and medicine) the use of both hierarchical and partitioning cluster methods is common (Pollard and van der Laan 2005), in the analysis of weed survey data, hierarchical clustering by means of dendrograms clearly dominates. However, there is no overall disadvantage of partitional clustering methods like kmeans clustering (allocating data between a number of a priori defined centroids) and their additional application is even recommended to test hierarchically clustered groups for their robustness (Fukami et al. 2005). An advantage of the nonhierarchical method partitioning around medoids (PAM) is that it allows clustering with respect to any specified distance metric (Kaufman and Rousseeuw 1990; van der Laan et al. 2003) including those that are able to deal with quantitative variables, e.g. the general dissimilarity coefficient of Gower (1971) (example in Hanzlik and Gerowitt 2011).

Usually, groupings found by clustering need some further verification in order to give ecological meaning to them. Especially the clustering of explanatory variables, e.g. to classify management effects within the data set, requires a subsequent procedure to examine whether the specific classification is of any significance for the weed vegetation. Indicator species analysis as described by Dufrene and Legendre (1997) is a robust tool to verify clustering results by determining the species whose presence and incidence best characterises the weed community of fields in different clusters. Phi-coefficient $(\Phi)$ and Ochiai index are other measures of fidelity that are commonly used by phytosociologists to quantify the preference of a species for a particular community in large sets of vegetation data (de Cáceres et al. 2008). Another less known but flexible and easily interpretable approaches to explore differences among groups of sites or species are classification and regression trees (CART) (McCune and Grace 2002; De'Ath and Fabricius 2000) which have been applied to survey data by Pyšek et al. (2005).

The described methods have been proven to be helpful in the reviewed analyses. However, there are more methods available, which could be checked by curious weed survey analysers for their additional value. Useful sources for the mathematical background to a multitude of both ordination and classification techniques are Legendre and Legendre (2008) and McCune and Grace (2002).

\subsection{Conclusions}

Survey data can be used to analyse and map single species or the diversity of species can be concentrated in coefficients. However, the amount of variables collected in large-scale surveys is best accounted for by multivariate approaches. From the variety of multivariate procedures, several have already proven to create extra value from weed survey data. We recommend weed scientists to apply these multivariate procedures, without discouraging them to explore others. Explanatory variables are of incredible importance for survey analyses to extract the background knowledge about the drivers of arable weed vegetation. 


\section{Summarizing survey results}

Due to the number of weed surveys and the many different species and landscapes involved, it is impossible to treat their results in detail. However, as they all share the agronomic objectives, a short summary of main conclusions from recent weed surveys is attempted at this place.

The majority of surveys that targeted the species composition of weed communities found similar factors to be important. In different surveys across Europe (Andersson and Milberg 1998; Hallgren et al. 1999; Lososová et al. 2004; Fried et al. 2008; Cimalová and Lososová 2009; Šilc et al. 2009; Hanzlik and Gerowitt 2011; Pinke et al. 2012) and even on other continents (Tamado and Milberg 2000; Qiang 2005), weed species composition was most affected by the crop, edaphic factors (especially soil $\mathrm{pH}$ and soil texture), season, altitude and climate. However, rankings of these factors are highly inconsistent between studies. On the one hand, this could be due to the specificity of each region; on the other hand, there are at least some indications for general trends. Firstly, the relative importance of climatic variables and altitude was found to decrease with decreasing length of gradients and thus potentially decreases with smaller spatial scale of a study (Lososová et al. 2004; Cimalová and Lososová 2009). However, the same variables are also known to decrease in their relative importance towards southern Europe as they are generally more favourable for the weed vegetation there (Holzner and Immonen 1982; Šilc et al. 2009; Pinke et al. 2010, 2012). Another interesting fact is that variables representing a geographical position or region usually affect species composition much more when they are expressed as eco-region or phytogeographical region (Andersson and Milberg 1998; Hallgren et al. 1999; Leeson et al. 2000; Šilc et al. 2009) rather than purely as latitude and longitude (Fried et al. 2008; Hanzlik and Gerowitt 2011). This suggests strong interactions with climatic and edaphic variables rather than a significant net effect of geographical position. Similarly, at least in canonical correspondence analysis, the relative importance of the factor 'crop' tends to be influenced by the number of individual crops included in the analysis due to mathematical properties of this method (Hallgren et al. 1999; Fried et al. 2008; Šilc et al. 2009).

Research on large-scale patterns of diversity (beta $(\beta)$ diversity) showed that weed vegetation varies less between fields. Under rather unfavourable environmental conditions, e.g. in higher altitudes, on sandy soils or under extreme soil reaction, this counts also within regions (Fried et al. 2008; Lososová et al. 2004; Šilc et al. 2008). No clear pattern was found for between-field differences due to crop type (Lososová and Cimalová 2009; Šilc et al. 2009) or farming system (Hawes et al. 2010).

There are also a number of weed surveys that aimed at examining changes in the abundance of weed species and/or the proportions of different species traits by comparing consecutive surveys of the same area (Table 1). While in Denmark and Finland the dominant weed species were largely the same in three consecutive surveys since the 1960s (Andreasen et al. 1996; Hyvönen et al. 2003; Andreasen and Stryhn 2008), in France, more than two thirds of the common weed species significantly changed their frequency rank status during the last 30 years (Fried et al. 2009). In contrast, for total weed abundance, a similar trend was observed in different parts of Europe. It shows a decreasing abundance and diversity of weeds from the beginning of wide applications of herbicides and levelling of site conditions until the 1980s but often increasing weed abundances during the last two decades due to herbicide reduction programmes, structural changes and a partial reversal of intensification (Andreasen et al. 1996; Hyvönen et al. 2003; Miloanova et al. 2007; Kapeluszny and Haliniarz 2007; Novák et al. 2009). However, this increase is rarely related to weed species of conservational value but usually involves higher proportions of problematic perennial and monocotyledonous species (Hyvönen et al. 2003; Novák et al. 2009; Potts et al. 2010; Pinke et al. 2011), higher abundances of generalist species that are common in all crops (Fried et al. 2010), nitrophilous weeds and weeds adapted to dense vegetation stands (Lososová et al. 2008; Šilc et al. 2009; Májeková et al. 2010).

Finally, the traditional phytosociological classification of weed associations was largely validated as it was found to coincide well with numerical classification by clustering of weed survey data (Lososová et al. 2006a; Šilc et al. 2008).

\section{Conclusions}

Despite the long history of weed surveys in arable situations, the plurality of sampling strategies is an issue in weed research, as is the exhaustive evaluation of survey data. With respect to different goals of and resources for surveys, we avoid to conclude an 'optimal' technic or protocol for all purposes; however, the increasing number of methodical approaches applied impedes comparisons and consolidations of different survey results. Strictly interpreted, the interaction of purpose and eligibility of survey data demand for specific approaches delivering data which exclusively answer the specific questions and is never used for any other purpose. However, times of widespread spatial modelling activities, accessible databases and biological data exploratories emphasise the opposite. With respect of the resources needed to obtain spatial data on arable weeds, it seems more rational to explore available data as much as possible and persuade users to do all analyses with caution and care.

Arable weeds are in general not the focus of national botanical surveying activities. Thus, long-term planned, repeated weed surveys organised by public authorities and done with 
public support are exceptional. To our knowledge, in Europe, this only applies to Hungary, Finland and Denmark. At least for the latter two, continuation does not seem guaranteed. In France, a national database for arable weeds exists (Fried et al. 2007), but continuous surveys are not reported. For a more global perspective, we found no recent example for organised, repeated surveys of arable weeds.

Opposite to this trend, information coming out of weed surveys receives increasing interest. Scientific approaches dealing with the effects of management methods or land use changes require these data. The most urgent need for weed survey data probably originates from spatial modelling and the simulation of climate change effects on weeds. As arable weeds will react on climate change on various scales, serious predictions about weeds have to rely on data of different scale, including a large scale (Peters et al. 2014). Any space or time projection either for selected species or for weed communities depends on proper spatial data from the region on which the projection is based. The ongoing scientific debate on the importance of management versus environmental factors on species diversity and composition would surely profit from additional survey material. We make two proposals to overcome this discrepancy of engagement and requirements:

First, weed scientists should make as much scientific extra value out of existing survey data as possible. This review hopefully contributes to this proposal. Successful attempts to this goal will help to increase the attractiveness of weed surveys for public donors.

While any public engagement in surveying weeds would be welcome, other solutions using innovative ways of project organisation seem necessary. Therefore, our second proposal is to establish public-private partnerships for weed surveys. Private partners, coming, e.g. from the herbicide industries, have a distinct interest in an overview on weed species distributions, have locally experienced people and can arrange access to farmers and fields. Research institutions, as public partners, have the methodological expertise to design the studies, to train the observers and to analyse the data. As a matter of course, unconfined access to the data and freedom to operate is indispensable for both partners. If these requirements are treated with caution and no interest of one of the two partners is causing any bias in the survey, valuable contributions to agronomic purposes can be obtained. Two surveys or parts of repeated surveys included in this overview provide examples for such public-private partnerships. While private partners are mainly interested in general species overviews and the results of first steps in data analyses, not necessarily published internationally (Mehrtens et al. 2005; Goerke et al. 2008), public partners can create extra value through more innovative data analyses (Hanzlik and Gerowitt 2011; De Mol et al. 2015).

Finally, an agreed upon common protocol about the methods of assessment would assist all joint activities with survey data. For agronomical purpose, we recommend some general cornerstones. However, regarding the high diversity and national European traditions in weed survey methods, setting widely accepted standards is a challenge which requires an organised, supranational interest in the data, which has not yet been expressed officially.

Acknowledgments The initial idea to conduct this review was born when KH was invited by the European Weed Research Society to contribute with a keynote presentation about possibilities to put additional value on weed mapping data. Thanks to Laurie Anne Koning for improving the manuscript with her native English skills.

\section{References}

Aavik T, Augenstein I, Bailey D, Herzog F, Zobel M, Liira J (2008) What is the role of local landscape structure in the vegetation composition of field boundaries? Appl Veg Sci 11:375-386. doi:10.3170/2008-718486

Andersson T, Milberg P (1998) Weed flora and the relative importance of site, crop, crop rotation and nitrogen. Weed Sci 46:30-38

Andreasen C, Skovgaard I (2009) Crop and soil factors of importance for the distribution of plant species on arable fields in Denmark. Agric Ecosyst Environ 133:61-67. doi:10.1016/j.agee.2009.05.003

Andreasen C, Stryhn H (2008) Increasing weed flora in Danish arable fields and its importance for biodiversity. Weed Res 48:1-9. doi:10. 1111/j.1365-3180.2008.00603.x

Andreasen C, Streibig J, Haas H (1991) Soil properties affecting the distribution of 37 weed species in Danish fields. Weed Res 31: 181-187

Andreasen C, Stryhn H, Streibig C (1996) Decline of the flora in Danish arable fields. J Appl Ecol 33:619-626

Andújar D, Ribeiro A, Carmona R, Fernández-Quintanilla C, Dorado J (2010) An assessment of the accuracy and consistency of human perception of weed cover. Weed Res 50:638-647. doi:10.1111/j. 1365-3180.2010.00809.x

Baessler C, Klotz S (2006) Effects of changes in agricultural land-use on landscape structure and arable weed vegetation over the last 50 years. Agric Ecosyst Environ 115:43-50. doi:10.1016/j.agee.2005. 12.007

Barnet DT, Stohlgren TJ, Jarnevich CS, Chong GW, Ericson JA, Davern TR, Simonson SE (2007) The art and science of weed mapping. Environ Monit Assess 132:235-252. doi:10.1007/s10661-0069530-0

Barralis G (1976) Méthode d'étude des groupements adventices des cultures annuelles. In: Proc 5éme Coll Int sur l'Ecologie et la Biologie des Mauvaises Herbes INRA 59-68

Borcard D, Legendre P, Drapeau P (1992) Partialling out the spatial component of ecological variation. Ecology 73:1045-1055

Braun-Blanquet J (1964) Pflanzensoziologie. Grundzüge der Vegetationskunde. Springer, Wien

Chancellor R (1977) A preliminary survey of arable weeds in Britain. Weed Res 17:283-287

Chancellor R, Froud-Williams R (1984) A second survey of cereal weeds in central southern England. Weed Res 24:29-36

Cimalová Š, Lososová Z (2009) Arable weed vegetation of the northeastern part of the Czech Republic: effects of environmental factors on species composition. Plant Ecol 203:45-57. doi:10.1007/s11258008-9503-1

Cousens RD, Dale MRT, Taylor J, Law R, Moerkerk M, Kembel SW (2006) Causes of pattern in plant communities where environmental 
change is rapid and species longevity is short. J Veg Sci 17:599-614. doi:10.1658/1100-9233(2006)17[599:COPIPC]2.0.CO;2

Dale MRT, Thomas AG, John EA (1992) Environmental factors including management practices as correlates of weed community composition in spring seeded crops. Can J Bot 70:1931-1939

de Cáceres M, Font X, Oliva F (2008) Assessing species diagnostic value in large data sets: a comparison between phi-coefficient and Ochiai index. J Veg Sci 19:779-788. doi:10.3170/2008-8-18446

De Mol F, Redwitz v C, Gerowitt B (2015) Weed species composition of maize fields in Germany is influenced by site and crop sequence. Weed Res. doi:10.1111/wre.12169, in print, online

De'Ath G, Fabricius KE (2000) Classification and regression trees: a powerful yet simple technique for ecological data analysis. Ecology 81:3178-3192

Derksen D (1996) Weed community ecology: tedious sampling or relevant science? A Canadian perspective. Phytoprotection 77:29-39

Derksen D, Thomas G, Lafond G, Loeppky H, Swanton C (1993) Impact of agronomic practices on weed communities: tillage systems. Weed Sci 41:409-417

Dufrene M, Legendre P (1997) Species assemblages and indicator species: the need for a flexible asymmetrical approach. Ecol Monogr 67:345-366

Ellenberg H, Weber HE, Düll R, Wirth V, Werner W, Paulißen D (1992) Zeigerwerte von Pflanzen in Mitteleuropa, 2nd edn. Goltze, Göttingen

Firbank L, Ellis N, Hill M, Lockwood A, Swetnam R (1998) Mapping the distribution of weeds in Great Britain in relation to national survey data and to soil type. Weed Res 38:1-10

Frick B, Thomas A (1992) Weed surveys in different tillage systems in southwestern Ontario field crops. Can J Plant Sci 72:1337-1347

Fried G, Reboud X, Gasquez J, Delos M (2007) 'Biovigilance Flore', a long-term French weed survey. Proc 20ème Conf du COLUMA 2007, 315-325

Fried G, Norton LR, Reboud X (2008) Environmental and management factors determining weed species composition and diversity in France. Agric Ecosyst Environ 128:68-76. doi:10.1016/j.agee. 2008.05.003

Fried G, Chauvel B, Reboud X (2009) A functional analysis of largescale temporal shifts from 1970 to 2000 in weed assemblages of sunflower crops in France. J Veg Sci 20:49-58. doi:10.1111/j. 1654-1103.2009.05284.x

Fried G, Petit S, Reboud X (2010) A specialist-generalist classification of the arable flora and its response to changes in agricultural practices. BMC Ecol 10, 20. doi:10.1186/1472-6785-10-20

Fukami T, Bezemer M, Mortimer S, van der Putten W (2005) Species divergence and trait convergence in experimental plant community assembly. Ecol Lett 8:1283-1290. doi:10.1111/j.1461-0248.2005. 00829.x

Gaba S, Chauvel B, Dessaint F, Bretagnolle V, Petit S (2010) Weed species richness in winter wheat increases with landscape heterogeneity. Agric Ecosyst Environ 138:318-323. doi:10.1007/s13593013-0166-5

Gabriel D, Roschewitz I, Tscharntke T, Thies C (2006) Beta diversity at different spatial scales: plant communities in organic and conventional agriculture. Ecol Appl 16:2011-2021. doi:10.1890/10510761(2006)016[2011:BDADSS]2.0.CO;2

Glemnitz M, Czimber G, Radicz L, Hoffmann J (2000) Weed flora composition along a north-south climate gradient in Europe. Acta Agronomica Ovariensis 42:155-169

Goerke K, Schönhammer A, Schulte M, Gerowitt B (2007) Weeds in oilseed rape in Germany - status and assessment of changes. In: Proc 14th EWRS Symp (ed. E Floistad), European Weed Research Society: 198

Goerke K, Richter U, Schulte M, Gerowitt B (2008) Regionale Unterschiede in der Rapsunkrautflora Deutschlands (Regional distinctions in the weed flora of winter oilseed rape in Germany). Ges Pfl 60:151-158. doi:10.1007/s10343-008-0193-3

Gower J (1971) A general coefficient of similarity and some of its properties. Biometrics 27:857-871

Gunton RM, Petit S, Gaba S (2011) Functional traits relating arable weed communities to crop characteristics. J Appl Veg Sci 22:541-550. doi:10.1111/j.1654-1103.2011.01273.x

Hallgren E (1996) Occurrence of broad-leaved weeds on different soils in different crops in Sweden. Swed J Agric Res 26:115-123

Hallgren E, Palmer M, Milberg P (1999) Data diving with cross-validation: an investigation of broad-scale gradients in Swedish weed communities. J Ecol 87:1037-1051

Hanzlik K, Gerowitt B (2011) The importance of climate, site and management on weed vegetation in oilseed rape in Germany. Agric Ecosyst Environ 141:323-331. doi:10.1016/j.agee.2011.03.010

Hanzlik K, Gerowitt B (2012) Occurrence and distribution of important weed species in Germany in winter oilseed rape. J Plant Dis Prot 119:107-120

Hawes C, Squire G, Hallett P, Watson C, Young M (2010) Arable plant communities as indicators of farming practice. Agric Ecosyst Environ 138:17-26. doi:10.1016/j.agee.2010.03.010

Hayek LC, Buzas MA (1997) Surveying natural populations. Columbia University Press, New York

Henderson PA (2003) Practical methods in ecology. Blackwell Science Ltd, Oxford

Hermy M (1988) Accuracy of visual cover assessments in predicting standing crop and environmental correlation in deciduous forests. Vegetatio 75:57-64

Hidalgo B, Saavedra M, Garcia-Torres L (1990) Weed flora of dryland crops in the Córdoba region (Spain). Weed Res 30:309-318

Hill M, Gauch H (1980) Detrended correspondence analysis, an improved ordination technique. Vegetatio 42:47-58

Holzner W, Immonen R (1982) The agrestal weed flora and vegetation of the world. In: Holzner W, Numata N (eds) Biology and ecology of weeds. Dr. W. Junk Publisher, The Hagues, pp 203-226

Hüppe J, Hofmeister H (1990) Syntaxonomische Fassung und Übersicht über die Ackerunkrautgesellschaften der Bundesrepublik Deutschland. Ber Reinhard-Tüxen-Ges 2:61-81

Hyvönen T, Ketoja E, Salonen J, Jalli H, Tiainen J (2003) Weed species diversity and community composition in organic and conventional cropping of spring cereals. Agric Ecosyst Environ 97:131-149. doi: 10.1016/S0167-8809(03)00117-8

Kapeluszny J, Haliniarz M (2007) Expanding segetal weed species in central-east Poland. In: Proc 14th EWRS Symp (ed. E Floistad) European Weed Res Society, 214

Kaufman L, Rousseeuw PJ (1990) Finding groups in data. Wiley, New York

Kenkel N, Derksen D, Thomas A, Watson P (2002) Review: multivariate analysis in weed science research. Weed Sci 50:281-292. doi:10. 1614/0043-1745(2002)050[0281:RMAIWS]2.0.CO;2

Kolářová M, Tyšer L, Soukup J (2013) Impact of site conditions and farming practices on the occurrence of rare and endangered weeds on arable land in the Czech Republic. Weed Res 53:489-498. doi 10.1111/wre. 12045

Kuzniewski E (1975) Ackerunkrautgesellschaften des südwestlichen Polen und die Auswertung ihrer Untersuchung für die Landwirtschaft. Vegetatio 30:55-60

Leeson J, Sheard J, Thomas A (1999) Multivariate classification of farming systems for use in integrated pest management studies. Can J Plant Sci 79:647-654

Leeson J, Sheard J, Thomas A (2000) Weed communities associated with arable Saskatchewan farm management systems. Can J Plant Sci 80: $177-185$

Legendre P, Legendre L (2008) Numerical ecology. Elsevier, Amsterdam Lepš J, Smilauer P (2003) Multivariate analysis of ecological data using CANOCO. Cambridge University Press, Cambridge 
Londo G (1976) The decimal scale for releves of permanent quadrats. Vegetatio 33:61-64

Lososová Z, Cimalová Š (2009) Effects of different cultivation types on native and alien weed species richness and diversity in Moravia (Czech Republic). J Basic Appl Ecol 10:456-465. doi:10.1016/j. baae.2008.11.001

Lososová Z, Chytrý M, Cimalová Š, Kropác Z, Otýpková Z, Pyšek P, Tichý L (2004) Weed vegetation of arable land in Central Europe: gradients of diversity and species composition. J Veg Sci 15:415422

Lososová Z, Chytrý M, Cimalová Š, Otýpková Z, Pyšek P, Tichý L (2006a) Classification of weed vegetation of arable land in the Czech Republic and Slovakia. Folia Geobotanica 41:259-273

Lososová Z, Chytrý M, Kühn I, Hájek O, Horáková V, Pyšek P, Tichý P, Tichý L (2006b) Patterns of plant traits in annual vegetation of manmade habitats in central Europe. Persp Plant Ecol Evol Systemat 8: 69-81. doi:10.1016/j.ppees.2006.07.001

Lososová Z, Chytrý M, Kühn I (2008) Plant attributes determining the regional abundance of weeds on central European arable land. J Biogeogr 35:177-187. doi:10.1111/j.1365-2699.2007.01778.x

Lutman P, Storkey J, Martin H, Holland J (2009) Abundance of weeds in arable fields in southern England in 2007/08. Asp Appl Biol 91:1-6

Magurran AE (2004) Measuring biological diversity. Blackwell Science, Malden

Májeková J, Zaliberová M, Šibík J, Klimová K (2010) Changes in segetal vegetation in the Borská nížina Lowland (Slovakia) over 50 years. Biologia 65:465-478

Marshall E, Arnold G (1995) Factors affecting field weed and field margin flora on a farm in Essex, UK. Landsc Urban Plan 31:205-216

McCloskey M, Firbank LG, Watkinson LG, Watkinson AR, Webb DJ (1996) The dynamics of experimental arable weed communities under different management practices. J Veg Sci 7:799-808

McCune B, Grace J (2002) Analysis of ecological communities. MjM Software Design, Glenden Beach

Médiène S, Valantin-Morison M, Sarthou J-P, de Tourdonnet S, Gosme M, Bertrand M, Roger-Estrade J, Aubertot J-N, Rusch A, Motisi N, Pelosi C, Doré T (2011) Agroecoystem management and biotic interactions: a review. Agron Sustain Dev 31:491-514. doi:10.1007/ s13593-011-0009-1

Mehrtens J, Schulte M, Hurle K (2005) Unkrautflora in Mais - Ergebnisse eines Monitorings in Deutschland. Ges Pfl 57:206-218

Meyer S, Wesche K, Krause B, Leuschner C (2013) Dramatic losses of specialist arable plants in Central Germany since the $1950 \mathrm{~s} / 60 \mathrm{~s}-\mathrm{a}$ cross-regional analysis. Divers Distrib 19:1175-1187. doi:10.1111/ ddi. 12102

Milberg P, Hallgren E, Palmer MW (2001) Timing of disturbance and vegetation development: how sowing date affects the weed flora in spring sown crops. J Veg Sci 12:93-98

Miloanova S, Boneva P, Grigorova P, Valkova M (2007) Weed survey in central north Bulgaria. In: Proc 14th EWRS Symp (ed. E Floistad) European Weed Research Society:217

Mueller-Dombois D, Ellenberg H (1974) Aims and methods of vegetation ecology. Wiley, New York

Mulugeta D, Stoltenberg DE, Boerboom CM (2001) Weed species-area relationships as influenced by tillage. Weed Sci 49:217-223

Murphy C, Lemerle D (2006) Continuous cropping systems and weed selection. Euphytica 148:61-73. doi:10.1007/s10681-006-5941-9

Novák R, Dancza I, Szentey L, Karamán J (2009) Arable weeds of Hungary - fifth national weed survey (2007-2008) (ed. R Novák), Ministry of Agriculture and Rural Development, Budapest (Hungary)

Onofri A, Carbonelle E, Piepho H, Mortimer A, Cousens RD (2010) Current statistical issues in weed research. Weed Res 50:5-24. doi: 10.1111/j.1365-3180.2009.00758.x

Peres-Neto P, Legendre P, Dray S, Borcard D (2006) Variation partitioning of species data matrices: estimation and comparison of fractions. Ecology 87:2614-2625. doi:10.1890/0012-9658(2006) 87[2614:VPOSDM]2.0.CO;2

Peters K, Breitsameter L, Gerowitt B (2014) Impact of climate change on weeds in agriculture - a review. Agron Sustain Dev 34:707-721. doi:10.1007/s13593-014-0245-2

Petit S, Boursault A, Le Guilloux M, Munier-Jolain N, Reboud X (2011) Weeds in agricultural landscapes. A review. Agron Sustain Dev 31: 309-317. doi:10.1051/agro/2010020

Petit S, Alignier A, Colbach N, Joannon A, Thenail C (2013) Weed dispersal by farming activities across spatial scales. Agron Sustain Dev 33:205-217. doi:10.1007/s13593-012-0095-8

Pinke G, Pál R (2008) Phytosociological and conservational study of the arable weed communities in western Hungary. Plant Biosystems 142:491-508. doi:10.1080/11263500802410843

Pinke G, Pál R, Botta-Dukát Z, Chytrý M (2009) Weed vegetation and its conservation value in three management systems of Hungarian winter cereals on base-rich soils. Weed Res 49:544-551. doi:10.1111/j. 1365-3180.2009.00730.x

Pinke G, Pál R, Botta-Dukát Z (2010) Effects of environmental factors on weed species composition of cereal and stubble fields in western Hungary. Cent Eur J Biol 5:283-292. doi:10.2478/s11535-0090079-0

Pinke G, Pál R, Tòth K, Karácsony P, Czúcz B, Botta-Dukát Z (2011) Weed vegetation of poppy (Papaver somniferum) fields in Hungary: effects of management and environmental factors on species composition. Weed Res 51:621-630. doi:10.1111/j.1365-3180.2011. 00885.x

Pinke G, Karácsony P, Czúcz B, Botta-Dukát Z, Lengyel A (2012) The influence of environment, management and site context on species composition of summer arable weed vegetation in Hungary. Appl Veg Sci 15:136-144. doi:10.1111/j.1654-109X.2011.01158.x

Poggio S, Satorre E, de la Fuente EB (2004) Structure of weed communities occurring in pea and wheat crops in the Rolling Pampa (Argentina). Agric Ecosyst Environ 103:225-235. doi:10.1016/j. agee.2003.09.015

Poggio S, Chaneton EJ, Ghersa CM (2013) The arable plant diversity of intensively managed farmland: effects of field position and crop type at local and landscape scales. Agric Ecosyst Environ 165:55-64. doi:10.1016/j.agee.2012.01.013

Pollard KS, van der Laan MJ (2005) Cluster analysis of genomic data. In: Gentleman R, Carey V, Huber W, Irizarry R, Dudoit S (eds) Bioinformatics and computational biology solutions using $\mathrm{R}$ and bioconductor, 1st edn. Springer, New York, pp 209-229

Pollnac FW, Maxwell B, Menalled FD (2009) Using species-area curves to examine weed communities in organic and conventional spring wheat systems. Weed Sci 57:241-247. doi:10.1614/WS-08-159.1

Potts G, Ewald J, Aebischer N (2010) Long-term changes in the flora of the cereal ecosystem on the Sussex Downs, England, focusing on the years 1968-2005. J Appl Ecol 47:215-226. doi:10.1111/j.13652664.2009.01742.x

Pyšek P, Jarošík V, Kropáč Z, Chytrý M, Wild J, Tichý L (2005) Effects of abiotic factors on species richness and cover in Central European weed communities. Agric Ecosyst Environ 109:1-8. doi:10.1016/j. agee.2005.02.018

Qiang S (2005) Multivariate analysis, description, and ecological interpretation of weed vegetation in the summer crop fields of Anhui Province, China. J Integr Plant Biol 47:1193-1210. doi:10.1111/j. 1744-7909.2005.00131.x

Raunkiaer C (1934) The life forms of plants and statistical plant geography. Clarendon, Oxford

Richner N, Holderegger R, Linders HP, Walter T (2015) Reviewing change in the arable flora of Europe: a meta-analysis. Weed Res 55:1-13. doi:10.1111/wre.12123

Rosenzweig M (1995) Species diversity in space and time. Cambridge University Press, Cambridge 
Saaverda M, Garcia-Torres L, Hernandez-Bermejo E, Hildalgo B (1990) Influence of environmental factors on the weed flora in crops in the Guadalquivir Valley. Weed Res 30:363-374

Salonen J (1993) Weed infestation and factors affecting weed incidence in spring cereals in Finland - a multivariate approach. Agric Sci Finl 2: $525-536$

Salonen J, Hyvönen T, Jalli H (2001) Weeds in spring cereal fields in Finland - a third survey. Agric Food Sci Finland 10:347-364

Schweiger O, Maelfait J, van Windgerden W, Hendrickx F, Billeter R, Speelmans M, Augenstein I, Aukema B, Aviron S, Bailey D, Bukacek R, Burel F, Diekötter T, Dirksen J, Frenzel M, Herzog F, Liira J, Roubalova M, Bugter R (2005) Quantifying the impact of environmental factors on arthropod communities in agricultural landscapes across organizational levels and spatial scales. J Appl Ecol 42:1129-1139. doi:10.1111/j.1365-2664.2005.01085.x

Šilc U (2008) Diversity of weed vegetation on arable land in Slovenia. J Plant Dis Prot XXI:351-356, Special Issue

Šilc U, Vrbnicanin S, Bozic D, Carni A, Daji C, Stevanovic (2008) Phytosociological alliances in the vegetation of arable fields in the northwestern Balkan Peninsula. Phytocoenologia 38:241-254. doi: 10.1127/0340-269X/2008/0038-0241

Šilc U, Vrbnicanin S, Bozic D, Carni A, Stevanovic Z (2009) Weed vegetation in the north-western Balkans: diversity and species composition. Weed Res 49:602-612. doi:10.1111/j.1365-3180.2009. 00726.x
Storkey J, Moss S, Cussans J (2010) Using assembly theory to explain changes in a weed flora in response to agricultural intensification. Weed Sci 58:39-46. doi:10.1614/WS-09-096.1

Sutcliffe O, Kay Q (2000) Changes in the arable flora of central southern England since the 1960s. Biol Conserv 93:1-8. doi:10.1016/S00063207(99)00119-6

Sykes JM, Horrill AD, Mountford MD (1983) Use of visual cover assessments as quantitative estimators of some British woodland taxa. J Ecol 71:437-450

Tamado T, Milberg P (2000) Weed flora in arable fields of eastern Ethiopia with emphasis on the occurrence of Parthenium hysterophorus. Weed Res 40:507-521. doi:10.1046/j.1365-3180. 2000.00208.x

Ter Braak C (1987) The analysis of vegetation-environment relationships by canonical correspondence analysis. Vegetatio 69:69-77

Thomas A (1985) Weed survey system used in Saskatchewan for cereal and oilseed crops. Weed Sci 33:34-43

van der Laan M, Pollard K, Bryan J (2003) A new partitioning around medoids algorithm. J StatComput Simul 73:575-584

Westhoff V, van der Maarel E (1978) The Braun-Blanquet approach. In: Whittaker RH (ed) Classification of plant communities, 2nd edn. Junk, The Hague, p 287-297

Whittaker R (1972) Evolution and measurement of species diversity. Taxon 21:213-251 